\title{
Introduction: Craniopharyngioma
}

\author{
Jeffrey H. Wisoff, M.D., ${ }^{1}$ John A. Jane Jr., ${ }^{2}$ Warren Selman, M.D., ${ }^{3}$ \\ and Rudolf Fahlbusch, M.D., Ph.D. ${ }^{4}$ \\ ${ }^{1}$ Division of Pediatric Neurosurgery, New York University Langone Medical Center, New York, New York, \\ ${ }^{2}$ Department of Neurosurgery, University of Virginia Health System, Charlottesville, Virginia; ${ }^{3}$ Department of \\ Neurological Surgery, University Hospitals Case Medical Center, Case Western Reserve University, \\ Cleveland, Ohio; and ${ }^{4}$ Neuroendocrine Surgery, International Neuroscience Institute, Hannover, Germany
}

$\mathrm{I}$ $\mathrm{N}$ the 8 decades since Cushing prophetically described craniopharyngiomas as "one of the most baffling problems to the neurosurgeon," 2 few subjects in neurosurgery have inspired more controversy than the management of these tumors. The rarity of these tumors has limited both individual neurosurgeons and most institutions from developing experience and expertise in their management: in the US, fewer than 350 craniopharyngiomas are diagnosed annually in the combined pediatric and adult population. ${ }^{1}$

The philosophy of curative treatment in patients with craniopharyngiomas is predicated on patients having unimpeded access to long-term medical care and the personal or societal financial resources for the costs of lifetime hormone replacement therapy. Both partial resection with adjuvant irradiation and primary gross-total resection carry similar rates of long-term disease control and recurrence in high-volume centers. ${ }^{3,5}$ This level of care is nearly universally available in North America, Western Europe, Japan, and other industrialized nations but may be extremely limited in other countries. Primary irradiation without resection, intracystic therapies, and palliative strategies may be more appropriate in those settings.

With excellent tumor control available from a variety of treatment paradigms, it is necessary to search for other clinical features or outcome parameters that may differentiate the risks and benefits for individual patients and to help fashion a cohesive therapeutic strategy. The ultimate test of which treatment approach will be appropriate may not depend on initial tumor control but rather the ability to salvage and cure patients with recurrent tumors in conjunction with an assessment of the impact of the treatment modality on the long-term quality of life. ${ }^{4}$

This issue of Neurosurgical Focus seeks to enhance our understanding of the biology, risk factors, therapeutic options, and long-term consequences of the management of craniopharyngioma. Four of the original articles provide insights into the pathogenesis and clinicopathology of craniopharyngiomas, describe a novel classification for stratifying the risk of hypothalamic injury in adults, present a proposal for a standardized metric to evaluate pre- and posttreatment functional status, and expand our knowledge of endocrine, ophthalmological, and vascular sequelae of treatment. Nuances of surgical management and an expansion of the results of endoscopic approaches are presented in 3 articles. Contemporary standards for radiation therapy are reviewed by Merchant and Kiehna while the paper by Veeravagu et al. describes advantages of stereotactic radiation techniques. The utilization of intracystic therapies is described by the Vancouver group. Cavalheiro and colleagues' presentation of the results of a multicenter study of intracystic interferon demonstrates both the efficacy of treatment and the necessity for multiinstitutional cooperative trials to provide therapeutic advances in this rare disease.

We hope that this issue of Neurosurgical Focus will be stimulating and challenge the reader to reassess his/her understanding of craniopharyngiomas and their treatment

\section{References}

1. Bunin GR, Surawicz TS, Witman PA, Preston-Martin S, Davis F, Bruner JM: The descriptive epidemiology of craniopharyngioma. J Neurosurg 89:547-551, 1998

2. Cushing $\mathrm{H}$ : The craniopharyngiomas, in Intracranial Tumors-Notes Upon a Series of Two Thousand Verified Cases with Surgical Mortality Percentages Thereto. Springfield, IL: Charles C Thomas, 1932

3. Merchant TE, Kiehna EN, Sanford RA, Mulhern RK, Thompson SJ, Wilson MW, et al: Craniopharyngioma: the St. Jude Children's Research Hospital experience 1984-2001. Int J Radiat Oncol Biol Phys 53:533-542, 2002

4. Sands SA, Milner JS, Goldberg J, Mukhi V, Moliterno JA, Maxfield C, et al: Quality of life and behavioral follow-up study of pediatric survivors of craniopharyngioma. J Neurosurg 103:302-311, 2005

5. Sanford RA: Craniopharyngioma: results of survey of the American Society of Pediatric Neurosurgery. Pediatr Neurosurg 21:39-43, 1994 